\title{
Plasma membrane calcium ATPase $4 b$ inhibits nitric oxide generation through calcium-induced dynamic interaction with neuronal nitric oxide synthase
}

\author{
Wenjuan Duan ${ }^{1 *}$, Juefei Zhou ${ }^{1,2^{*}}$, Wei Li ${ }^{3 *}$, Teng Zhou ${ }^{1,4}$, Qianqian Chen ${ }^{1,4}$, Fuyu Yang ${ }^{1 凶}$, Taotao Wei $^{1 \bowtie}$ \\ ${ }^{1}$ National Laboratory of Biomacromolecules, Institute of Biophysics, Chinese Academy of Sciences, Beijing 100101, China \\ ${ }^{2}$ Research Department of Bacterial Vaccine, Chengdu Institute of Biological Products Co. Ltd, Chengdu 610023, China \\ ${ }^{3}$ State Key Laboratory of Virology, Wuhan Institute of Virology, Chinese Academy of Sciences, Wuhan 430071, China \\ ${ }^{4}$ University of Chinese Academy of Sciences, Beijing 100049, China \\ $\triangle$ Corresponding authors: yangfy@sun5.ibp.ac.cn (F. Yang), weitt@moon.ibp.ac.cn (T. Wei) \\ Received November 12, 2013 Accepted February 15, 2013
}

\section{ABSTRACT}

The activation and deactivation of $\mathrm{Ca}^{2+}$ - and calmodulindependent neuronal nitric oxide synthase (nNOS) in the central nervous system must be tightly controlled to prevent excessive nitric oxide (NO) generation. Considering plasma membrane calcium ATPase (PMCA) is a key deactivator of nNOS, the present investigation aims to determine the key events involved in nNOS deactivation of by PMCA in living cells to maintain its cellular context. Using time-resolved Förster resonance energy transfer (FRET), we determined the occurrence of $\mathrm{Ca}^{2+}$-induced protein-protein interactions between plasma membrane calcium ATPase 4b (PMCA4b) and nNOS in living cells. PMCA activation significantly decreased the intracellular $\mathrm{Ca}^{2+}$ concentrations $\left(\left[\mathrm{Ca}^{2+}\right]_{\mathrm{i}}\right)$, which deactivates nNOS and slowdowns NO synthesis. Under the basal $\left[\mathrm{Ca}^{2+}\right]_{i}$ caused by PMCA activation, no protein-protein interactions were observed between PMCA4b and nNOS. Furthermore, both the PDZ domain of $n N O S$ and the PDZ-binding motif of PMCA4b were essential for the protein-protein interaction. The involvement of lipid raft microdomains on the activity of PMCA4b and nNOS was also investigated. Unlike other PMCA isoforms, PMCA4 was relatively more concentrated in the raft fractions. Disruption of lipid rafts altered the intracellular localization of PMCA4b and affected the interaction between PMCA4b and nNOS, which suggest that the unique lipid raft distribution of PMCA4 may be respon- sible for its regulation of nNOS activity. In summary, lipid rafts may act as platforms for the PMCA4b regulation of nNOS activity and the transient tethering of nNOS to PMCA4b is responsible for rapid nNOS deactivation.

KEYWORDS plasma membrane calcium ATPase, neuronal nitric oxide synthase, calcium, nitric oxide, lipid raft, Förster resonance energy transfer

\section{INTRODUCTION}

Nitric oxide (NO) is synthesized from oxygen and l-arginine by nitric oxide synthase (NOS) and has essential roles in vascular tone modulation, neurotransmission, and immune defense (Moncada and Bolanos, 2006). Three genetically different isoforms of NOS account for NO production, namely, the two constitutive forms endothelial nitric oxide synthase (eNOS) and neuronal nitric oxide synthase (nNOS) and the inducible form inducible nitric oxide synthase (iNOS). Among these isoforms, nNOS (also known as NOS-I) is the isoform predominantly found in neuronal tissue (Alderton et al., 2001). NO production by activated nNOS in the central nervous system is triggered by elevated intracellular $\mathrm{Ca}^{2+}$ concentrations $\left(\left[\mathrm{Ca}^{2+}\right]_{\mathrm{i}}\right)$ and it has been associated with the induction and maintenance of synaptic plasticity. NO may also regulate neurosecretory control (Calabrese et al., 2007). However, aside from the physiologic functions mentioned above, NO becomes noxious when produced in excess (Pacher et al., 2007). Superfluous NO has

\footnotetext{
*These authors contributed equally to the work.
} 
been closely associated with the risk of the developing brain ischemia damage, Parkinson's disease, Alzheimer's disease, and other nervous system diseases (Torreilles et al., 1999; Tran et al., 2003; Moro et al., 2004; Guix et al., 2005). Based on the physiologic and pathologic role of $\mathrm{NO}$, the generation, release, diffusion, and deactivation of NO should be precisely regulated in the central nervous system, which is accomplished mainly through nNOS activation and deactivation.

The NO synthesis catalyzed by nNOS is $\mathrm{Ca}^{2+}$-dependent and the regulation of nNOS activity is closely related to the structure of nNOS. The nNOS monomer (inactive form) has a bidomain structure, wherein an oxygenase domain ( $\mathrm{N}$ terminus) that contains binding sites for heme, $\mathrm{BH}_{4}$, and Iarginine is linked by a calmodulin-binding motif to a reductase domain (C-terminus) that contains binding sites for FAD, FMN, and NADPH (Alderton et al., 2001; Sagami et al., 2001; Zhou and Zhu, 2009). In addition, the N-terminus of nNOS contains a PDZ domain that participates in the formation of active dimers and interacts with other proteins in the specific regions of the cell (Zhou and Zhu, 2009). nNOS is anchored to the second PDZ domain of PSD-95 through the interaction between the PDZ domains, while PSD-95 is bound to NMDA receptors (NMDA-R) through the PDZ domain. This indirect anchoring positions nNOS and NMDA-R close to each other, thereby greatly increasing the efficiency of the conversion from excitatory amino acids signals to NO signals (Brenman et al., 1996). Meanwhile, excess NO leads to the nitrosylation of the Cys $^{744}$ and Cys $^{798}$ of the NMDA-R, which deactivates NMDA$\mathrm{R}$ and decreases $\mathrm{Ca}^{2+}$ influx (Kim et al., 1999). Therefore, the contiguity of nNOS and NMDA-R increases the sensitivity and speed of negative feedback regulation.

Compared with nNOS activation, less is known about the key events during nNOS deactivation. Using biochemical approaches, Schuh et al. found that the PDZ binding motif at the C-terminus of plasma membrane calcium ATPase $4 \mathrm{~b}$ (PMCA4b) interacts with the PDZ domain of nNOS. Based on these findings, Schuh suggested that PMCA is a major factor that downregulates nNOS activity (Schuh et al., 2001).

In the present investigation, we used time-resolved Förster resonance energy transfer (FRET) to monitor the transient protein-protein interactions between PMCA and nNOS in living cells and simultaneously monitored the changes in intracellular $\mathrm{Ca}^{2+}$ concentrations $\left(\left[\mathrm{Ca}^{2+}\right]_{\mathrm{i}}\right)$ and $\mathrm{NO}$ concentrations $\left([\mathrm{NO}]_{\mathrm{i}}\right)$. We found that the increase in $\left[\mathrm{Ca}^{2+}\right]_{i}$ induced protein-protein interaction between PMCA4b and nNOS contributes to nNOS deactivation. We also found that the interaction between PMCA4b and nNOS depends on the PDZ domain and the integrity of the lipid rafts. These events may play an important role in controlling NO production in the central nervous system.

\section{RESULTS}

Expression and partitioning profiles of PMCA isoforms in rat brains

We first analyzed the expression profiles of the four PMCA isoforms (PMCA1, PMCA2, PMCA3, and PMCA4) in adult rat brains at both the mRNA level and the protein level. The four PMCA isoforms were expressed in the four functional regions of the brain we tested, namely, the cerebral cortex, cerebellar cortex, hippocampus, and corpus striatum, as shown in Fig. $1 \mathrm{~A}$ and $1 \mathrm{~B}$. Then, we investigated the partitioning of these $\mathrm{PMCA}$ isoforms in the brain plasma membrane microdomains. We fractionated the brain plasma membrane using the methods described by Sepúlveda et al. (2006), and found that all four PMCA isoforms are associated with the low density fractions (lipid raft microdomains); however, PMCA4 was relatively enriched in the lipid rafts compared with the other isoforms (Fig. 1C).

\section{Impairment of lipid rafts affected the localization of PMCA4 and nNOS}

nNOS expression was relatively higher in the cerebellum (Fig. 2A); thus, we used primary cerebellar granule cells, a relatively homogenous and well-characterized culture system of cerebellar neurons (Dudek et al., 1997), to investigate the subcellular localization of endogenous PMCA4 and nNOS in neuronal cells. We also observed the subcellular localization of nNOS in HEK-293 cells transfected with pcDNA3.1-nNOS vector. The immunofluorescence images clearly indicate that PMCA4 has typical membrane protein distribution, whereas the endogenous and exogenous nNOS have cytoplasmic distributions (Fig. 2B).

The intracellular localization of PMCA and nNOS was further investigated in living cells that expressed fused proteins. The HEK-293 cells transfected with pEGFP-hPMCA4b and pRFP-nNOS were used to observe the localization of PMCA4 and nNOS. The intracellular distribution patterns of PMCA4bEGFP and nNOS-RFP were similar to the immunocytochemistry results, as shown in Fig. $2 \mathrm{C}$. The merged image indicated the partial colocalization of PMCA4b-EGFP and nNOS-RFP at the plasma membrane.

The cell fractionation results indicate that PMCA4 is relatively enriched in lipid rafts; hence, we investigated the influence of lipid rafts on the intracellular localization of PMCA4 and nNOS. After treatment with $M \beta C D$, the lipid raft microdomains of the plasma membrane were disrupted and the membrane lipids were remodeled. Consequently, PMCA4b was redistributed in the plasma membrane, forming a relatively homogenous pattern, whereas nNOS was dispersed in the cytoplasm, which caused the disappearance of the partial colocalization of PMCA4b-EGFP and nNOS-RFP.

Increase in $\left[\mathrm{Ca}^{2+}\right]_{\mathrm{i}}$ activated PMCA and nNOS in living cells

We measured the activity of PMCA and nNOS in living cells using $\mathrm{Ca}^{2+}$-specific Fura-2-AM and NO-specific DAF-2-DA fluorescence probes, respectively. Isosmotic buffer containing $\mathrm{N}$-methyl-d-glucamine was used to block the $\mathrm{Ca}^{2+}$ transport mediated by the $\mathrm{Na}^{+}-\mathrm{Ca}^{2+}$ exchanger (NCX), whereas thapsigargin was added to inhibit the activity of the endoplasmic re- 
A

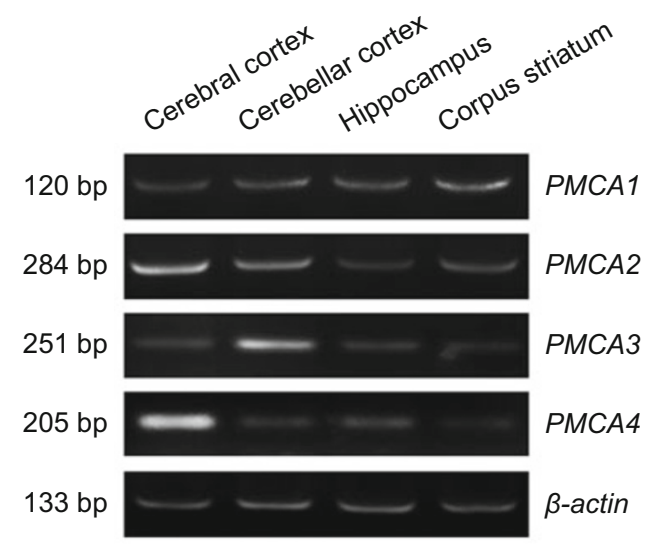

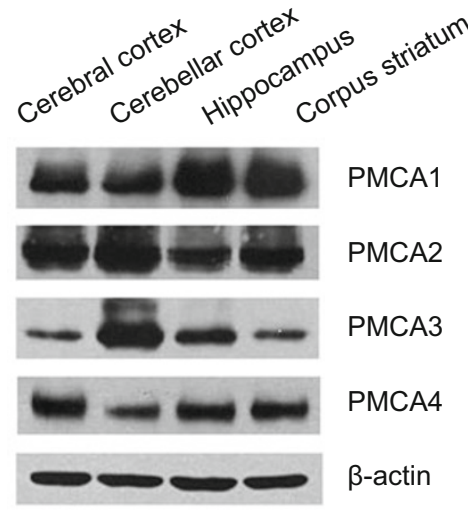

C Fraction number

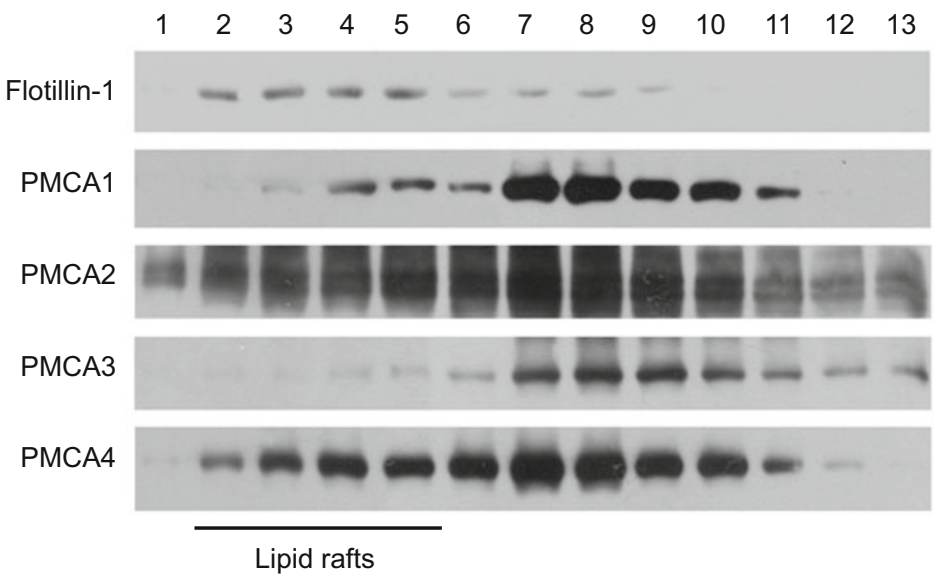

Figure 1. Expression and partitioning profiles of four PMCA isoforms in adult rat brains. (A) mRNA expression profiles of four PMCA isoforms. RNA was isolated from the cerebral cortex, cerebellar cortex, hippocampus, and corpus striatum and subjected to RTPCR to analyze the expression of PMCA1, PMCA2, PMCA3, and PMCA4. $\beta$-Actin was used as the internal standard. (B) Protein expression profiles of the four PMCA isoforms. Proteins were extracted from the cerebral cortex, cerebellar cortex, hippocampus, and corpus striatum, and $20 \mu \mathrm{g}$ of each sample was subjected to SDS-PAGE and immunoblotted with antibodies against PMCA1, PMCA2, PMCA3, and PMCA4. $\beta$-Actin was used as the internal standard. (C) Partitioning of the four PMCA isoforms in the microdomains of the plasma membrane of neuronal cells. The plasma membrane was fractionized into lipid rafts or non-raft fractions using a Nycodenz density gradient. Approximately, $11 \mu \mathrm{L}$ of the 13 fractions was subjected to $7.5 \%$ SDS-PAGE and immunoblotted with antibodies against the PMCA isoforms. Flotillin-1 was used as the marker for lipid raft fractions.

ticulum $\mathrm{Ca}^{2+}$-ATPase. In the presence of $\mathrm{N}$-methyl-d-glucamine and thapsigargin, the decrease in $\left[\mathrm{Ca}^{2+}\right]_{i}$ solely depends on PMCA activation.

We first measured the activity of endogenous PMCA and nNOS in cerebellar granule cells by monitoring the changes in $\left[\mathrm{Ca}^{2+}\right]_{i}$ and $[\mathrm{NO}]_{i}$. After the addition of glutamate, the glutamate receptor on the plasma membrane was activated and the receptor-coupled $\mathrm{Ca}^{2+}$ channel was opened, causing a rapid influx of $\mathrm{Ca}^{2+}$ into the cells. The drastic increase in $\left[\mathrm{Ca}^{2+}\right]_{i}$ rapidly activated the PMCA, which transports $\mathrm{Ca}^{2+}$ out of the cells. The PMCA activation gradually returns $\left[\mathrm{Ca}^{2+}\right]_{i}$ to the quiescent levels (Fig. $3 \mathrm{~A})$. High $\left[\mathrm{Ca}^{2+}\right]_{\mathrm{i}}$ levels also activate nNOS, triggers NO generation (Fig. $3 \mathrm{C}$ ). The $\mathrm{M} \beta \mathrm{CD}$ treatment markedly slowed down the decrease in $\left[\mathrm{Ca}^{2+}\right]_{i}(\mathrm{Fig} .3 \mathrm{~B})$, and the glutamate-treated cerebellar granule cells were unable to generate NO (Fig. 3D), which suggests that the integrity of lipid rafts also has an important role in the activation of PMCA and nNOS.

Subsequently, we measured the changes in $\left[\mathrm{Ca}^{2+}\right]_{i}$ and $\left[\mathrm{NO}_{\mathrm{i}}\right.$ in HEK-293 cells. Exposure of HEK-293 cells to thapsigargin and ionomycin triggered the release of $\mathrm{Ca}^{2+}$ from the endoplasmic reticulum and significantly increased the $\left[\mathrm{Ca}^{2+}\right]$, which rapidly activated PMCA. Activated PMCA gradually decreased the $\left[\mathrm{Ca}^{2+}\right]_{\mathrm{i}}$ to basal levels (Fig. 4A). High $\left[\mathrm{Ca}^{2+}\right]_{\mathrm{i}}$ levels also activated nNOS in the HEK-293 cells transfected with pcDNA3.1nNOS, which triggered the generation of $\mathrm{NO}$ (Fig. 4C). Treatment with $M \beta C D$ also limited the elimination of $\mathrm{Ca}^{2+}$ (Fig. 4B) 


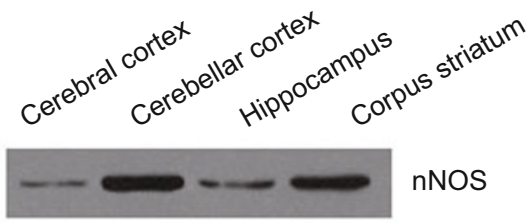

$\mathrm{C}$

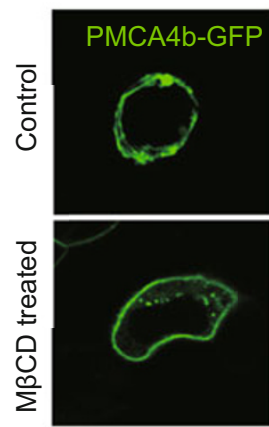

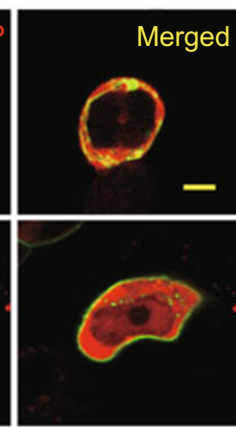

B
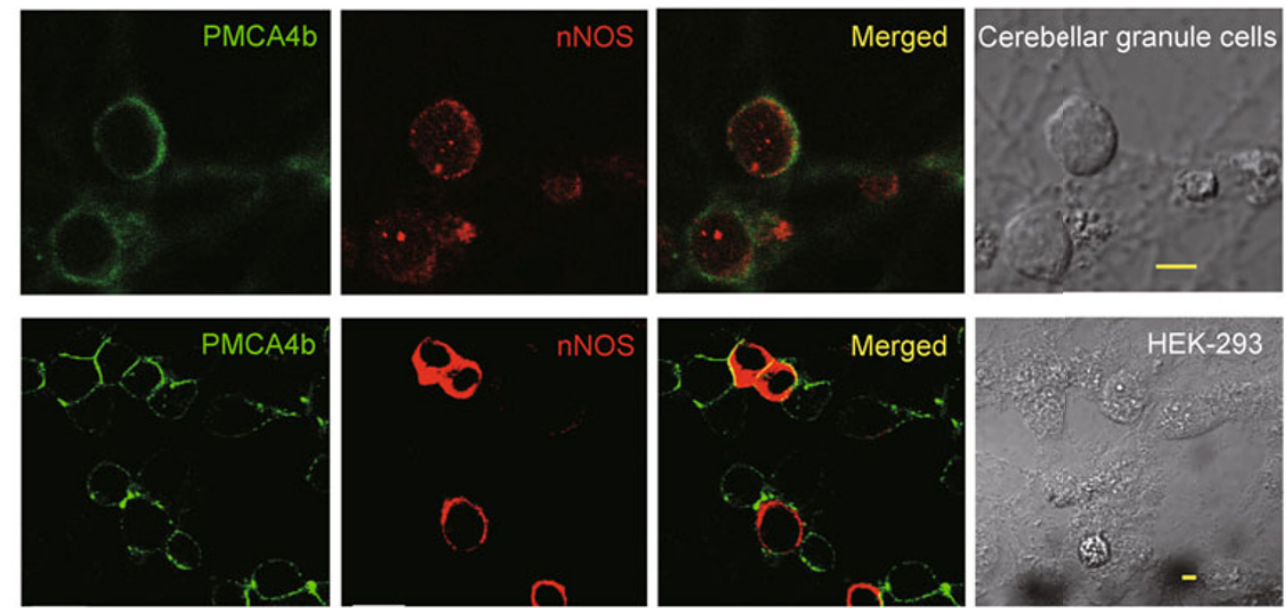

Figure 2. Intracellular localization of PMCA4b and nNOS in cerebellar granule cells and HEK-293 cells. (A) Protein expression profiles of nNOS. Proteins were extracted from the cerebral cortex, cerebellar cortex, hippocampus, and corpus striatum. Then, $20 \mu \mathrm{g}$ of each sample was subjected to SDS-PAGE and then immunoblotted with antibodies against nNOS. (B) Immunofluorescence micrographs of primary cerebellar granule cells and HEK-293 cells transfected with pcDNA3.1-nNOS. Red, nNOS; green, PMCA4b. (C) Fluorescence micrographs of PMCA4b (fused with EGFP) and nNOS (fused with RFP) expression in HEK-293 cells. HEK-293 cells were cotransfected with pEGFP-hPMCA4b and pRFP-nNOS. In some experiments, the cells were pretreated with M $B C D$ to disrupt lipid raft integrity. Bar, $5 \mu \mathrm{m}$.

and blocked the generation of NO (Fig. 4D).

\section{Increased PMCA activity decreased NO generation}

We cotransfected HEK-293 cells with different amounts of pcDNA3.1-myc-PMCA4b and with $1 \mu \mathrm{g}$ of pcDNA3.1-nNOS to manipulate their PMCA activity. Exposure of cells to thapsigargin and ionomycin triggered the $\mathrm{Ca}^{2+}$-dependent activation of PMCA and nNOS. Transfection with pcDNA3.1-myc-PMCA4b plasmids caused the dose-dependent expression of exogenous PMCA4b proteins, as shown in Fig. 5A. In addition, the increase in PMCA4b protein levels was correlated with the increase in PMCA activity (Fig. 5B). Transfecting more PMCA4b expression plasmids increased the $\mathrm{Ca}^{2+}$-elimination speed. The total PMCA activity of HEK-293 cells transfected with $2 \mu \mathrm{g}$ of PMCA4b plasmids was about twice that of cells transfected with empty vectors.

We also detected the nNOS-generated NO in HEK-293 cells simultaneously cotransfected with pcDNA3.1-nNOS and
pcDNA3.1-myc-PMCA4b, and found that HEK-293 cells with higher PMCA4b activities generated less NO (Fig. 5C). These results suggest that $\mathrm{PMCA} 4 \mathrm{~b}$ is one of the key molecules that deactivated nNOS.

$\mathrm{Ca}^{2+}$-induced transient protein-protein interaction between PMCA4b and nNOS was mediated by PDZ domain and depended on the integrity of lipid rafts

\section{Construction of vectors and intracellular localization of fused proteins}

Time-resolved FRET was used in living cells to study the protein-protein interaction between PMCA4b and nNOS under physiologic conditions. EGFP fused with PMCA4b and RFP fused with nNOS were used as donor-acceptor pairs. A series of vectors that encode the fused EGFP and PMCA4b protein or the fused RFP and nNOS protein were constructed with pEGFP-N1 vector or pDsRed/monomer C1 vector, respec- 


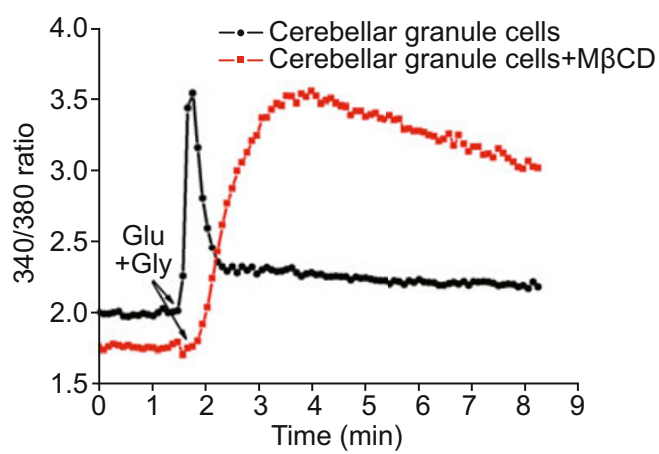

C

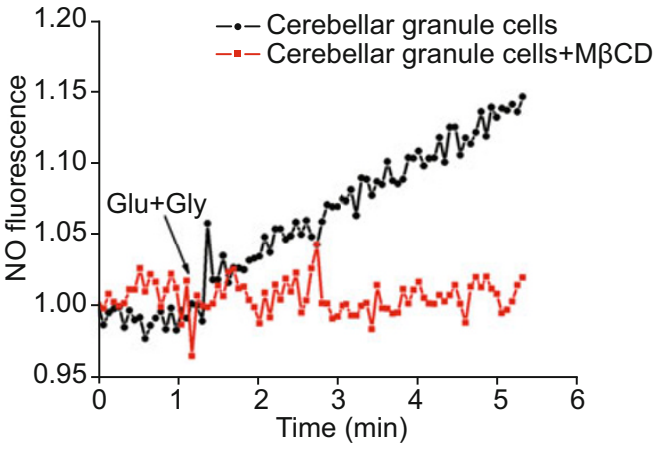

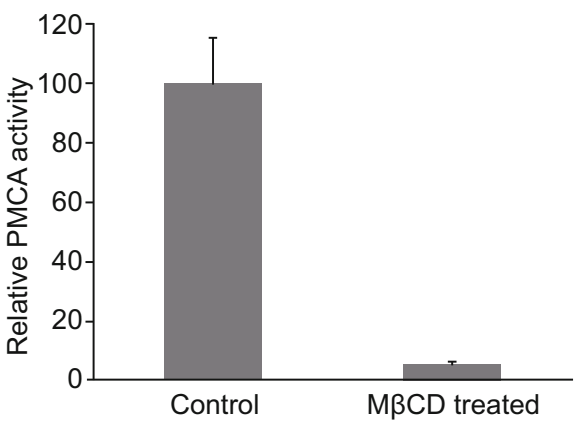

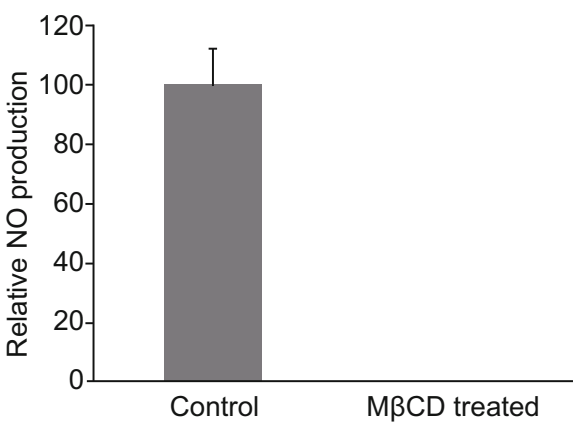

Figure 3. Changes in $\left[\mathrm{Ca}^{2+}\right]_{\mathrm{i}}$ and $[N]_{i}$ in cerebellar granule cells.(A) Glutamate-induced increase in $\left[\mathrm{Ca}^{2+}\right]_{i}$ in cerebellar granule cells. Primary cerebellar granule cells were loaded with a $\mathrm{Ca}^{2+}$-sensitive cell-permeable Fura-2-AM probe, and then treated with glutamate and glycine. The changes in fluorescence at $340 \mathrm{~nm} / 380 \mathrm{~nm}$ excitation and $510 \mathrm{~nm}$ emission wavelengths were recorded under a Nikon TE2000 fluorescence microscope. Glutamate/glycine caused a drastic increase in $\left[\mathrm{Ca}^{2+}\right]_{\mathrm{i}}$ via the activation of glutamate receptor. (B) Quantitative determination of PMCA activity. Increased $\left[\mathrm{Ca}^{2+}\right]_{\mathrm{i}}$ activates PMCA, which causes a rapid decrease in $\left[\mathrm{Ca}{ }^{2+}\right]_{i}$. The speed of $\mathrm{Ca}^{2+}$ efflux from cells reflects PMCA activity. Disruption of lipid rafts by M $B C D$ causes a marked decrease in PMCA activity. (C) Glutamate-induced increase in [NO], in cerebellar granule cells. Primary cerebellar granule cells were loaded with the NO-sensitive cellpermeable DAF-2-DA probe and then treated with glutamate and glycine. The changes in fluorescence at $490 \mathrm{~nm}$ excitation and $520 \mathrm{~nm}$ emission wavelengths were recorded under a Nikon TE2000 fluorescence microscope. (D) Quantitative determination of nNOS activity. Disruption of lipid rafts by MBCD markedly decreased nNOS activity.

tively (Fig. 6A). The pEGFP-hPMCA4b-mut vector carried an $\mathrm{Asp}^{672} \rightarrow$ Glu mutation that reduced the ATPase activity to about $10 \%$. The pEGFP-hPMCA4b-cap vector contained a myc/6× His tag at the C-terminus of PMCA4b, which blocks the binding to PDZ domains (Adamo et al., 1995). The pRFP$\triangle \mathrm{nNOS}$ vector, which encodes a fused nNOS-RFP protein with a deleted PDZ-domain, was also constructed to investigate the involvement of PDZ domain in the protein-protein interactions between PMCA4b and nNOS. The intracellular localization of fused proteins was examined under confocal microscopy. Neither the mutation of $\mathrm{Asp}^{672} \rightarrow$ Glu nor the myc/6× His tag affected the membrane localization of PMCA (Fig. 6B).

\section{$\mathrm{Ca}^{2+}$-induced transient protein-protein interaction between PMCA4b and nNOS}

We investigated the protein-protein interaction between PMCA4b and nNOS in HEK-293 cells transfected with vectors that encode the fused PMCA4b and nNOS protein. The time course of the occurrence of FRET is shown in Fig. 6C. In quiescent cells with low $\left[\mathrm{Ca}^{2+}\right]_{\mathrm{i}}$, both PMCA and nNOS were kept in inactive form and no energy transfer occurred between hPMCA4b-EGFP and nNOS-RFP. However, when the cells were treated with thapsigargin and ionomycin, the $\mathrm{Ca}^{2+}$ was released from intracellular calcium pools (mainly form endoplasmic reticulum) into the cytoplasm and the $\left[\mathrm{Ca}^{2+}\right]_{i}$ reached high levels. Under these conditions, both PMCA4b and nNOS were activated. At $30 \mathrm{~s}$ after the addition of thapsigargin and ionomycin, the fluorescence intensity of PMCA4b-EGFP decreased, whereas that of nNOS-RFP increased, which suggests the occurrence of FRET between PMCA4b-EGFP and nNOS-RFP. That is, thapsigargin and ionomycin treatment initiated the increase in $\left[\mathrm{Ca}^{2+}\right]_{\mathrm{i}}$, which triggered the protein-protein interaction between PMCA4b and nNOS. Interestingly, the protein-protein interaction between PMCA4b and nNOS was highly dynamic and dependent on $\left[\mathrm{Ca}^{2+}\right]_{\mathrm{i}}$. At $160 \mathrm{~s}$ after the addition of thapsigargin and ionomycin, the $\left[\mathrm{Ca}^{2+}\right]_{\mathrm{i}}$ decreased 


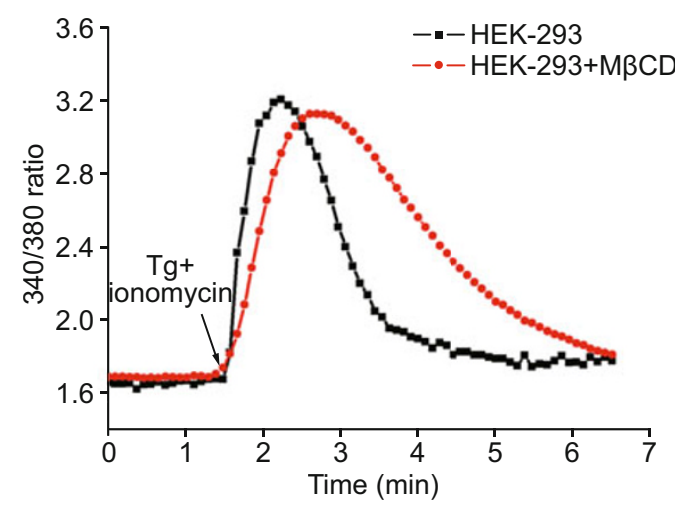

C

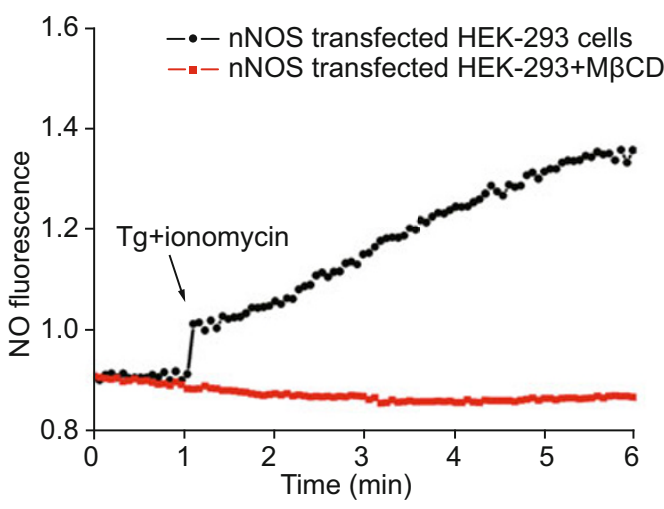

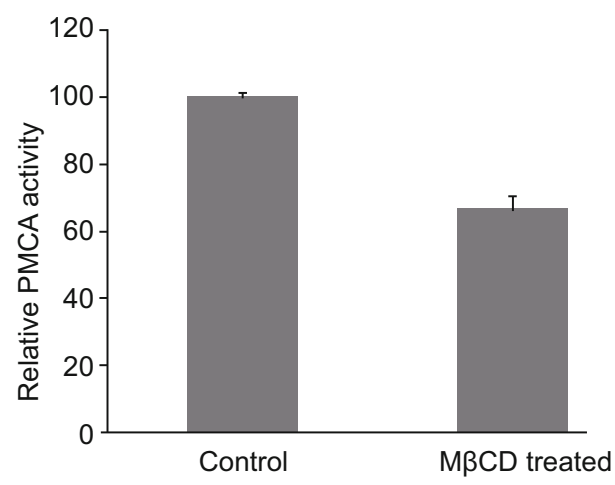

$\mathrm{D}$

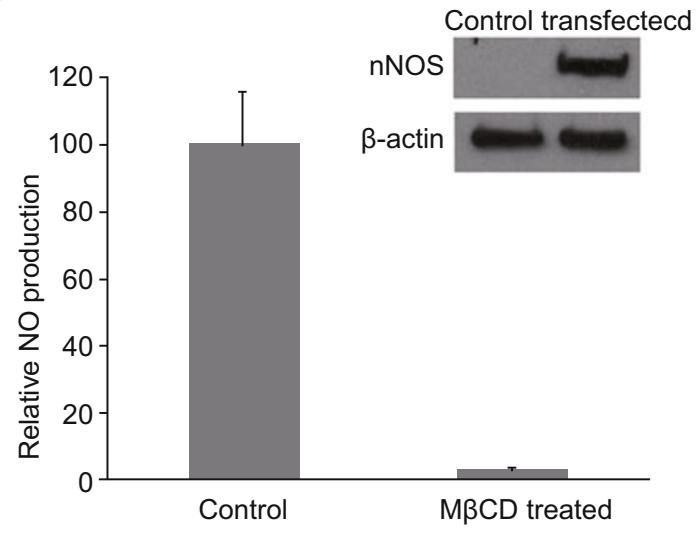

Figure 4. Changes in $\left[\mathrm{Ca}^{2+}\right]_{\mathrm{i}}$ and $[\mathrm{NO}]_{\mathrm{i}}$ in HEK-293 cells. (A) Thapsigargin and ionomycin-induced increase in $\left[\mathrm{Ca}^{2+}\right]_{\mathrm{i}}$ in $\mathrm{HEK}-293$ cells. HEK-293 cells were transfected with pcDNA3.1-nNOS for $48 \mathrm{~h}$, loaded with the $\mathrm{Ca}^{2+}$-sensitive cell-permeable Fura-2-AM probe and then treated with thapsigargin and ionomycin. The changes in fluorescence at 340/380 nm were recorded under a Nikon TE2000 fluorescence microscope. Thapsigargin and ionomycin drastically increased the $\left[\mathrm{Ca}^{2+}\right]_{i \cdot}$ (B) Quantitative determination of PMCA activity. The increased $\left[\mathrm{Ca}^{2+}\right]_{i}$ activates PMCA, which rapidly decreased the $\left[\mathrm{Ca}^{2+}\right]_{\mathrm{i}}$. The speed of $\mathrm{Ca}^{2+}$ efflux reflects the PMCA activity. Disruption of lipid rafts by M $B C D$ markedly decreased the PMCA activity. (C) Calcium-dependent, thapsigargin and ionomycin-induced increase in [NO], in HEK293 cells. HEK-293 cells transfected with pcDNA3.1-nNOS were loaded with the NO-sensitive cell-permeable DAF-2-DA probe and then treated with thapsigargin and ionomycin. The changes in fluorescence intensity from $510 \mathrm{~nm}$ to $540 \mathrm{~nm}$ were recorded under a Nikon TE2000 fluorescence microscope. (D) Quantitative determination of nNOS activity. Disruption of lipid rafts by M $\beta C D$ marked decreased the nNOS activity.

to basal levels and the FRET between PMCA4b-EGFP and nNOS-RFP disappeared.

Comparison of the FRET that occurred between hPMCA4bEGFP/nNOS-RFP and hPMCA4b-mut-GFP/nNOS-RFP revealed that the maximal $\mathrm{nF}$ of the HEK-293 cells transfected with pEGFP-hPMCA4b-mut (lower ATPase activity) was 54, whereas that of the HEK-293 cells transfected with pEGFPhPMCA4b (normal ATPase activity) was 42. The difference in FRET intensity may be due to the difference in PMCA activity. The overexpression of functional hPMCA4b fused proteins enhanced PMCA activity, which increased the $\mathrm{Ca}^{2+}$-elimination machinery. The rapid decline in $\left[\mathrm{Ca}^{2+}\right]_{i}$ in the HEK-293 cells transfected with pEGFP-hPMCA4b significantly decreased the protein-protein interaction between PMCA4b and nNOS.
Importance of the PDZ domain and the lipid rafts in the protein-protein interaction between PMCA4b and nNOS

We further investigated the effects of the PDZ domain of $n N O S$ and the PDZ-binding motif of PMCA4b on the proteinprotein interaction between PMCA4b and nNOS. The PDZ domain of nNOS (1-299 aa) was deleted by constructing the vector $\mathrm{pRFP}-\triangle \mathrm{nNOS}$. Transfection with the vector $\mathrm{pEGFP}$ hPMCA4b-cap blocked the binding of the myc/6× His tag at the C-terminus of PMCA4b to the PDZ domains (Adamo et al., 1995). No apparent FRET was observed in the HEK-293 cells cotransfected with pEGFP-hPMCA4b-cap plus pRFP-nNOS, or pEGFP-hPMCA4b-mut plus pRFP- $\triangle \mathrm{nNOS}$, which suggests that both the C-terminus PDZ binding motif of PMCA4b and the PDZ domain of nNOS were crucial for the protein-protein 


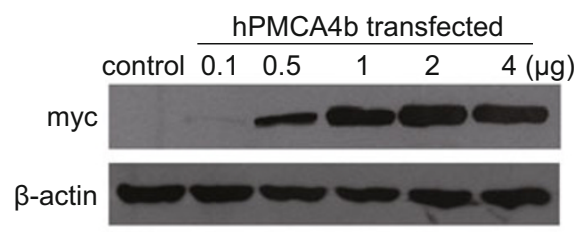

B

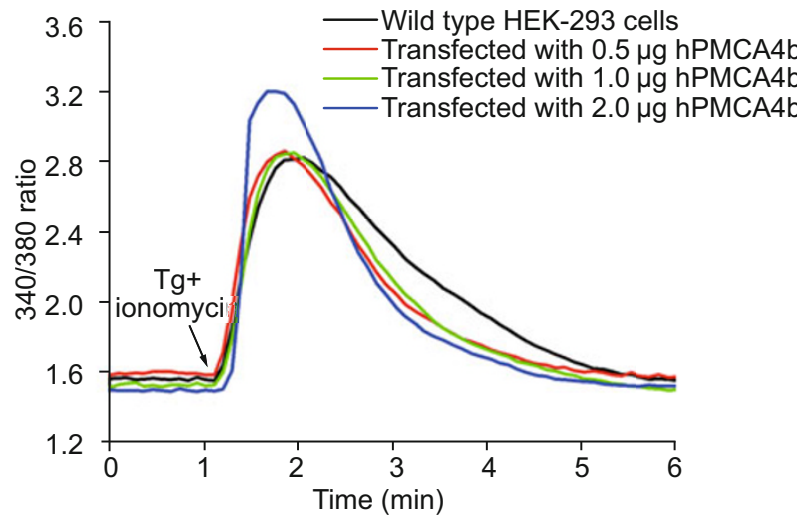

C

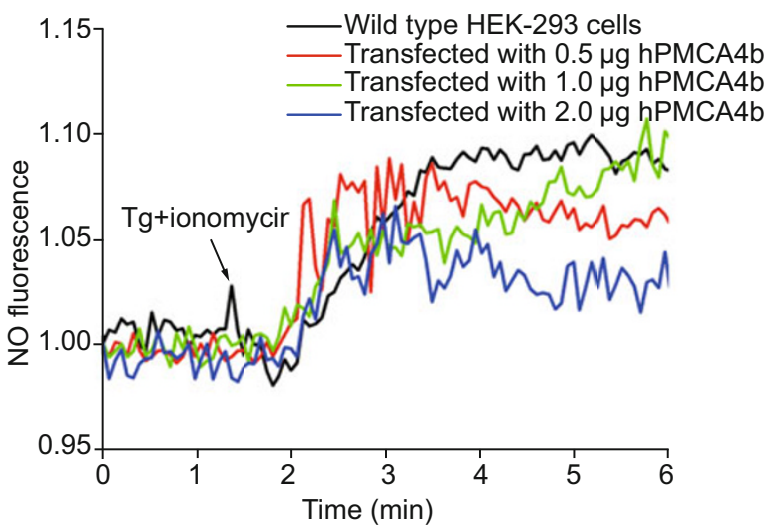

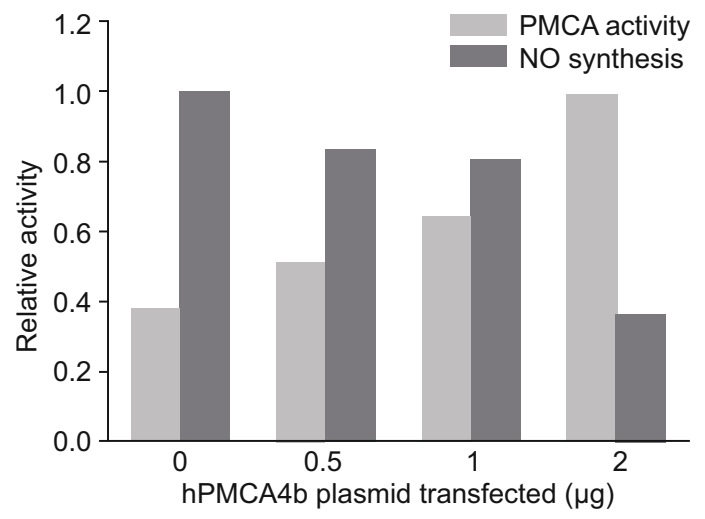

Figure 5. Increase in PMCA4b activity negatively regulates nNOS. (A) Expression of myc-tagged PMCA4b. HEK-293 cells were transfected with different amounts of pcDNA3.1-mycPMCA4b for $48 \mathrm{~h}$, and PMCA4b expression of was analyzed via western blot analysis using anti-myc antibody. (B) Changes in $\left[\mathrm{Ca}^{2+}\right]_{\mathrm{i}}$ in HEK-293 cells. HEK-293 cells were cotransfected with pcDNA3.1-myc-PMCA4b and pcDNA3.1-nNOS for $48 \mathrm{~h}$, loaded with the $\mathrm{Ca}^{2+}$-sensitive cell-permeable Fura-2-AM probe and then treated with thapsigargin and ionomycin. The changes in fluorescence intensity at $340 / 380 \mathrm{~nm}$ were recorded under a Nikon TE2000 fluorescence microscope. (C) Changes in of [NO]i in HEK-293 cells. HEK-293 cells were transfected with pcDNA3.1myc-PMCA4b and pcDNA3.1-nNOS for 48 h, loaded with the NOsensitive cell-permeable DAF-2-DA probe and then treated with thapsigargin and ionomycin. The changes in fluorescence intensity from $510-530 \mathrm{~nm}$ were recorded under a Nikon TE2000 fluorescence microscope. (D) Quantitative determination of PMCA and $\mathrm{nNOS}$ activity.

interaction between PMCA4b and nNOS.

The influence of lipid rafts on the interaction between PMCA4b and nNOS was also investigated. We found that pretreatment of the cells with $M B C D$ abolished the interaction between PMCA4b and nNOS, which indicated that the integrity of the lipid raft microdomains is needed for the interaction of these two proteins.

\section{DISCUSSION}

$\mathrm{Ca}^{2+}$ is essential for regulating a large number of fundamental cellular physiologic functions (Carafoli, 2003); thus, the changes in $\left[\mathrm{Ca}^{2+}\right]_{i}$ must be tightly regulated. Membrane proteins such as calcium ATPases (also known as calcium pumps) and sodium/calcium exchangers are responsible for transporting $\mathrm{Ca}^{2+}$ across the membrane (Brini and Carafoli, 2009). Calcium ATPases anchored to the plasma membrane (PMCA) have a high affinity for $\mathrm{Ca}^{2+}$ and they precisely control $\mathrm{Ca}^{2+}$ signals

to ensure the accurate transmission (target/effector and amplitude/frequency) of the signals (Brini, 2009; Oceandy et al., 2010). In mammals, PMCAs are encoded by a multigene family (ATP2B1-ATP2B4) to form four isoforms: PMCA1, PMCA2, PMCA3, and PMCA4. PMCA1 and PMCA4 are ubiquitous, whereas PMCA2 and PMCA3 are much more restricted to certain tissues. Two main variants, denoted as PMCAa and PM$\mathrm{CAb}$, were observed from the alternate splicing of the mRNA transcripts at the C-terminus splice site of PMCA (Kruger et al., 2009). More than 30 different spliced forms of PMCA have been identified (Guerini, 1998; Strehler and Zacharias, 2001), which have been associated with the high complexity and temporal/spatial specificity of the $\mathrm{Ca}^{2+}$ signals.

PMCA4 is ubiquitously expressed in mammalian cells and is regarded as a key modulator of $\mathrm{Ca}^{2+}$-related signaling in neuronal cells (Kim et al., 1998; Schuh et al., 2001), cardiomyocytes (Oceandy et al., 2007), and endothelial cells (Holton et al., 2010). The PMCA4b splice variant contains a PDZ-binding 
motif that allows it to interact with the PDZ domains of other proteins. Several of these interacting proteins have been identified in neuronal cells, including membrane-associated guanylate kinase (MAGUK) (Kim et al., 1998), calcium/calmodulin- dependent serine protein kinase (CASK) (Schuh et al., 2003), Ania-3 (Sgambato-Faure et al., 2006), and nNOS (Schuh et al., 2001). The interaction between PMCA4b and nNOS has been investigated systematically by Neyses et al., (Schuh et

A

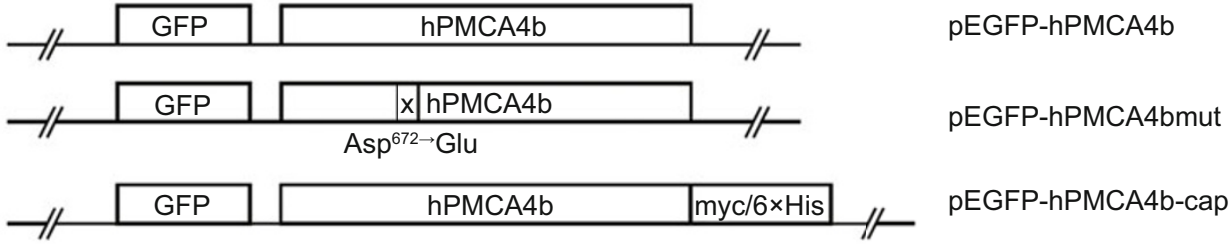

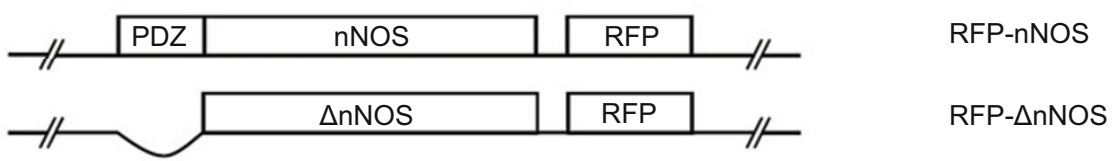

B

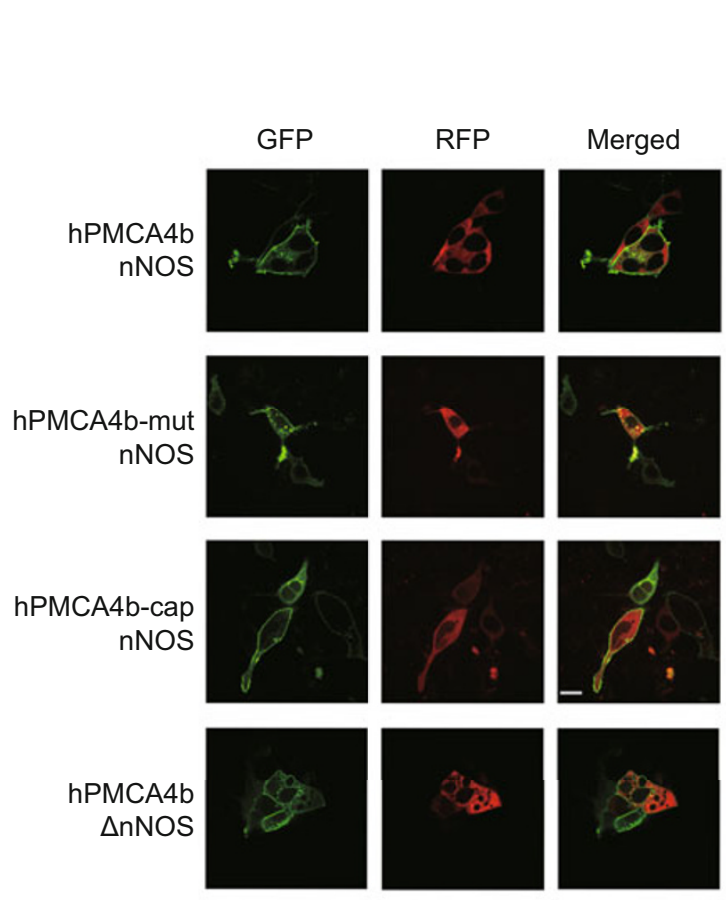

C

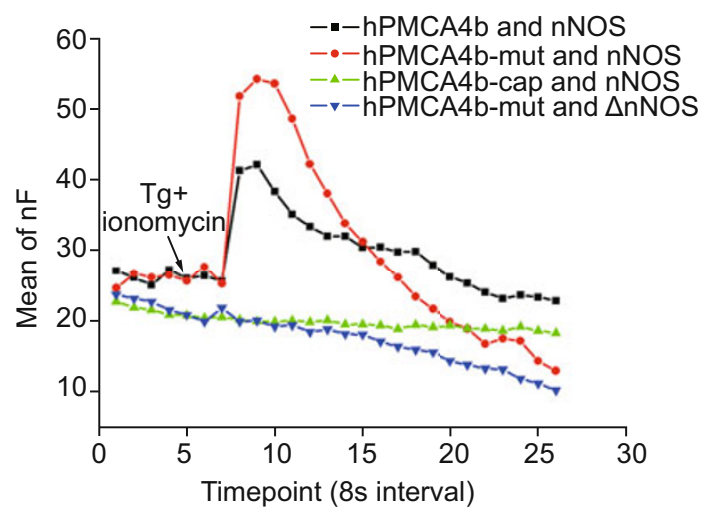

D

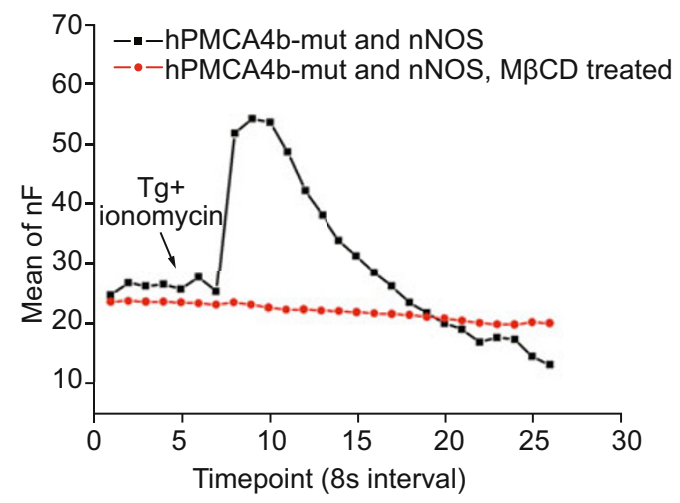

Figure 6. Changes in $\mathrm{Ca}^{2+}$-induced fluorescence resonance energy transfer between PMCA4b and nNOS. (A) Plasmid constructs used in FRET. pEGFP-hPMCA4b containing full-length human PMCA4b sequences. pEGFP-hPMCA4b-mut carried an Asp ${ }^{672} \rightarrow$ Glu mutation, which causes a $\sim 90 \%$ decrease in ATPase activity. pEGFP-hPMCA4b-cap contains a myc/6× His tag that caps the PDZ-binding C-terminus of PMCA4b. pRFP-nNOS contains the full-length nNOS sequence. pRFP- $\triangle$ nNOS contains part of the nNOS sequence without an interacting PDZ domain (1-299 aa). (B) Expression and intracellular localization of fused proteins in HEK-293 cells. HEK-293 cells were transfected with the plasmids for $48 \mathrm{~h}$, and then visualized under a PerkinElmer UltraVIEW VoX confocal microscope system. Bar, 15 $\mu \mathrm{m}$. (C) Changes in FRET in HEK-293 cells. HEK-293 cells were transfected with the plasmids for $48 \mathrm{~h}$, and then treated with thapsigargin and ionomycin. The changes in FRET between PMCA (green; donor) and nNOS (red; acceptor) were recorded under a Perkin Elmer UltraVIEW VoX confocal microscope system. Cells were imaged at $8 \mathrm{~s}$-intervals for $208 \mathrm{~s}$. The curves with different colors represent the changes in $\mathrm{nF}$. (D) Disruption of lipid rafts blocked the occurrence of FRET. HEK-293 cells were transfected with pEGFP-hPMCA4b-mut and RFP-nNOS for $48 \mathrm{~h}$, with and without MßCD pretreatment, and then treated with thapsigargin and ionomycin. The changes in FRET between PMCA and nNOS were recorded. 


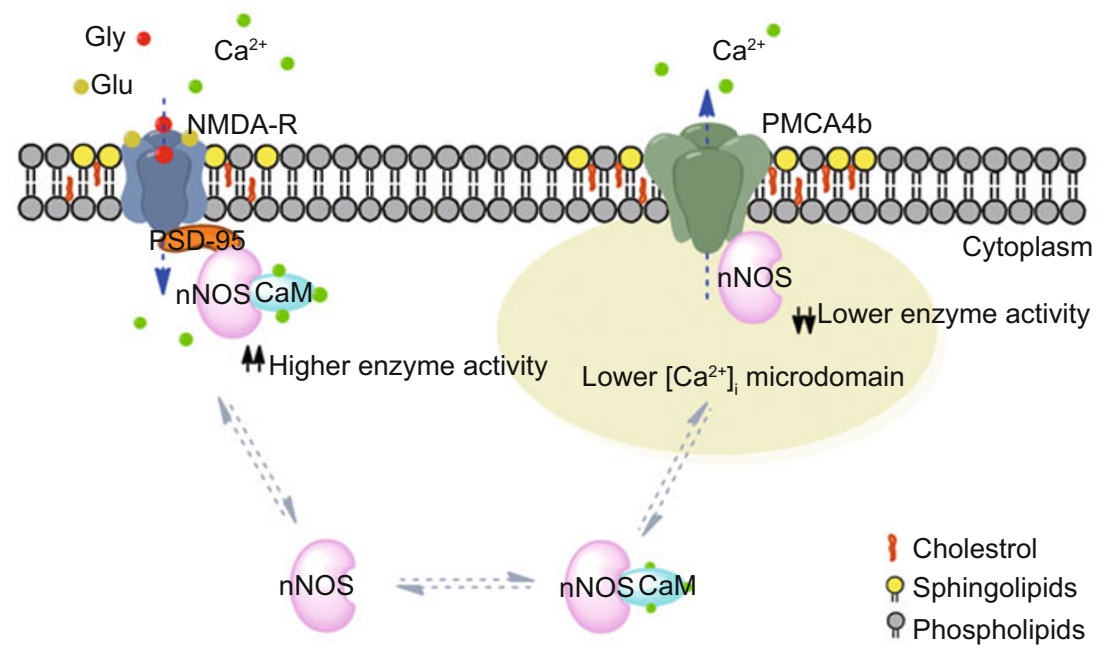

Figure 7. Activation and deactivation of nNOS in neurons. PMCA4b decreased the local $\left[\mathrm{Ca}^{2+}\right]_{\mathrm{i}}$ levels by transporting $\mathrm{Ca}^{2+}$ out of the cells, thereby downregulating the nNOS activity dynamically associated with PMCA4b via Ca ${ }^{2+}$-dependent, PDZ domain-mediated protein-protein interactions. The lipid rafts rich in PMCA4b may act as platforms by which PMCA4b regulates nNOS activity.

al., 2001; Oceandy et al., 2007), and they hypothesized that PMCA4b may be the key modulator of nNOS deactivation (Mohamed et al., 2009, 2011). However, investigating the function of proteins and protein networks in the cell should be preferably performed in vivo to maintain the cellular context (Piehler, 2005).

Considering the highly dynamic nature of transmembrane proteins (Ciruela, 2008; Loura and Prieto, 2011; Miyawaki, 2011), we employed FRET instead of biochemical approaches to investigate the interaction between PMCA4b and nNOS in living cells. The results of the time-resolved FRET clearly indicated energy transfer between PMCA4b and nNOS, which suggests the occurrence of protein-protein interactions (Fig. 6). More importantly, we found that the interaction is highly dynamic. The transient FRET only occurs under high $\left[\mathrm{Ca}^{2+}\right]_{\mathrm{i}}$. No FRET was observed under basal $\left[\mathrm{Ca}^{2+}\right]_{\mathrm{i}}$ caused by PMCA activation. We also found that both the PDZ domain of nNOS and the PDZbinding motif of PMCA4b are essential for the interaction in living cells, which is in accordance with the results obtained using cell-free systems (Schuh et al., 2001).

The interaction between PMCA4b and nNOS depends on $\left[\mathrm{Ca}^{2+}\right]_{\mathrm{i}}$; thus, we determined how $\mathrm{Ca}^{2+}$ modulates the proteinprotein interactions. As a P-type ATPase, the C-terminus of PMCA has a self-inhibitory effect. Under physiologic conditions when certain cellular events increase the intracellular free $\mathrm{Ca}^{2+}$ concentrations , the $\mathrm{Ca}^{2+}$-mediated binding of calmodulin to the C-terminus of PMCA prevents the self-inhibition, thereby activating PMCA (Falchetto et al., 1991; Falchetto et al., 1992; Kobe and Kemp, 1999). Using intramolecular FRET technology, Gerardo confirmed the rearrangement of the $\mathrm{N}$ - and the C-terminal segments of PMCA during activation (Corradi and Adamo, 2007). Based on these reports, we speculated that the $\mathrm{Ca}^{2+}$-mediated rearrangement of PMCA provides the structural basis for the protein-protein interactions.
The present investigation found that the integrity of lipid rafts is necessary for the protein-protein interaction and the activation of PMCA4b and nNOS. The distribution of PMCA in the plasma membrane microdomains differs in different cell types. In endothelial cells, smooth muscle cells, and cardiac muscle cells, the PMCA4b is localized in the caveolae, a specialized subset of lipid rafts (Fujimoto, 1993; Hammes et al., 1998). Our results indicate that PMCA4b is relatively enriched in the lipid rafts of neuronal plasma membranes (Fig. 1C), which was in accordance with previous reports (Sepulveda et al., 2006). The partitioning of PMCA4b in lipid rafts suggests that it exerts certain functions related to lipid rafts. Lipid rafts are thought to dynamically organize cellular signaling events triggered by extracellular stimuli (Simons and Ikonen, 1997; Brown and London, 1998). A large number of signaling molecules are situated in these subcellular microdomains, and a considerable amount of molecular signal, including $\mathrm{Ca}^{2+}$, may reach lipid rafts (Parton, 2001). In this regard, PMCA4b displays its key role, selecting the target for the calcium signal (Oceandy et al., 2010). A recent study revealed that lipid raftanchored PMCA has higher activity than PMCA localized in non-raft microdomains (Jiang et al., 2007). In addition to other cellular compartments, nNOS has also been shown to be localized to caveolae in several cell types including muscle cells (Stamler and Meissner, 2001; Cartwright et al., 2009). The caveolae of cardiomyocytes have been regarded as platforms for assembling PMCA4/nNOS/ a1-syntrophin signaling complexes (Williams et al., 2006). Our findings further suggest the importance of lipid rafts for PMCA4/nNOS interaction in neuronal cells.

Controlling the local $\left[\mathrm{Ca}^{2+}\right]_{\mathrm{i}}$ has an important role during nNOS activation in neuronal cells. By interacting with scaffolding proteins such as PSD95, nNOS and NMDA-R form signaling complexes at the neuronal plasma membrane, where the $\mathrm{Ca}^{2+}$ influx rapidly activates nNOS (Brenman et al., 1996). 
Similar mechanisms may also be involved in the deactivation of nNOS. PMCA4b, which is enriched in lipid rafts with high $\mathrm{Ca}^{2+}$ affinity, changes into its active form under elevated $\left[\mathrm{Ca}^{2+}\right]_{\mathrm{i}}$ (Corradi and Adamo, 2007); thus, it interacts rapidly with nNOS via PDZ-related interactions. Activated PMCA4b rapidly decreases the local $\mathrm{Ca}^{2+}$, which rapidly decreases nNOS activity. Lower local $\left[\mathrm{Ca}^{2+}\right]_{\mathrm{i}}$ also initiates the rearrangement of PMCA and releases the interaction with nNOS (Fig. 7).

In conclusion, we provide direct evidence that increasing $\left[\mathrm{Ca}^{2+}\right]_{i}$ triggers a transient interaction between PMCA4b and nNOS in living cells, which depends on the integrity of lipid rafts. By transporting $\mathrm{Ca}^{2+}$ out of the cells, the PMCA4b enriched in lipid rafts decreases the local $\left[\mathrm{Ca}^{2+}\right]_{\mathrm{i}}$ levels, thereby downregulating the nNOS activity dynamically associated to PMCA4b via $\mathrm{Ca}^{2+}$-dependent PDZ domain-mediated proteinprotein interactions. Lipid rafts may act as platforms for the regulation of $\mathrm{nNOS}$ activity by PMCA4b, and the transient tethering of $n N O S$ to PMCA4b is responsible for the rapid deactivation of nNOS.

\section{MATERIALS AND METHODS}

Antibodies and chemicals

Primary antibodies against PMCA1, PMCA2, PMCA3, and PMCA4 were obtained from Affinity Bioreagents. The primary antibodies against nNOS were from Cell Signaling Technology, whereas the primary antibodies against $\beta$-actin were from Santa Cruz. The primary antibodies against flotillin-1 were from BD Biosciences. HRP-, FITC-, and TRITC-conjugated secondary antibodies were from Santa Cruz. Dulbecco's modified Eagle's medium (DMEM), fetal bovine serum, cell culture supplements, TRIzol ${ }^{\mathrm{TM}}$, Lipofectamine ${ }^{\mathrm{TM}}$ 2000, and Fura-2-AM were from Invitrogen. DAF-2-DA, thapsigargin, and ionomycin were from Merck. All other chemicals were from Sigma.

\section{Recombinant DNA constructs}

The plasmids pCMV-hPMCA4b, pCMV-hPMCA4b-mut, and pCMVhPMCA4b-cap were generously provided by Dr. Ludwig Neyses (University of Manchester, UK). The plasmids pcDNA3.1-nNOS and pEGFP-hPMCA4b were kindly provided by Dr. Rohini Kuner (University of Heidelberg, Germany) and Dr. Stanley A. Thayer (University of Minnesota, USA), respectively.

The pRFP-nNOS plasmid that expresses a fused RFP and rat $\mathrm{nNOS}$ protein was generated using the $\mathrm{pDsRed} /$ monomer $\mathrm{C} 1$ vector (Clontech) at the Xhol and EcoRI sites. The pRFP- $\triangle$ nNOS plasmid that expresses a fused RFP and rat nNOS protein without an interacting PDZ domain (1-299 aa) deleted was generated using the same method. The pEGFP-hPMCA4b plasmid that expresses a fused EGFP and human PMCA4b protein, the pEGFP-hPMCA4b-mut plasmid that expresses a fused EGFP and human PMCA4b protein with an $A_{s p}{ }^{672} \rightarrow$ Glu mutation, and the pEGFP-hPMCA4b-cap plasmid that expresses a fused protein EGFP and human PMCA4b protein with a myc/6x His tag at the PMCA4b C-terminus were generated using the pEGFP-N1 vector (Clontech) at the Xhol and BamHI sites (Schuh et al., 2001). The pcDNA3.1-myc-hPMCA4b plasmid that expresses a myc-tagged human PMCA4b was constructed using a pcDNA3.1(-) vector at the BamHI and Kpnl sites.

\section{Cell culture and transfection}

Primary cultures of cerebellar granule cells were prepared from 7-dayold Sprague-Dawley rat pups (Beijing Vital River Experimental Animal Center). The cerebella were dissected and trypsinized at $37^{\circ} \mathrm{C}$ for 20 min. Trypsinization was terminated using fetal bovine serum, and the cells were mechanically dissociated by pipetting up and down for 5 times. The cells were resuspended in high-glucose DMEM supplemented with $10 \%$ fetal bovine serum, penicillin $(100 \mathrm{U} / \mathrm{mL})$, streptomycin $(100 \mu \mathrm{g} / \mathrm{mL})$, and $25 \mathrm{mmol} / \mathrm{L} \mathrm{KCl}$, and were seeded into $35 \mathrm{~mm}$-dishes previously coated with poly-d-lysine $(100 \mu \mathrm{g} / \mathrm{mL})$. The cells were maintained in a humidified incubator containing $5 \% \mathrm{CO}_{2}$ and $8 \% \mathrm{O}_{2}$ at $37^{\circ} \mathrm{C}$. At $24 \mathrm{~h}$ after seeding, cytosine arabinoside $(10 \mu \mathrm{mol} / \mathrm{L})$ was added into the medium to inhibit the growth of non-neuronal cells. The cells were ready for use on the seventh day.

HEK-293 cells were grown in high-glucose DMEM supplemented with $10 \%$ fetal bovine serum, penicillin $(100 \mathrm{U} / \mathrm{mL})$, and streptomycin $(100 \mu \mathrm{g} / \mathrm{mL})$, and maintained in a humidified $5 \% \mathrm{CO}_{2} /$ air incubator at $37^{\circ} \mathrm{C}$. The cells were transfected with various vectors using Lipofectamine $^{\mathrm{TM}} 2000$ reagent. The cells were used for experiments at $48 \mathrm{~h}$ after transfection.

Isolation of synaptic plasma membrane and separation of lipid rafts

The protocol for synaptic plasma membrane (SPM) isolation was kindly provided by Dr. Pingsheng Liu (Institute of Biophysics, CAS). Briefly, the brains of six Sprague-Dawley rats were collected and kept in $0.3 \mathrm{~mol} / \mathrm{L}$ sucrose on ice. The forebrains were homogenized using 20 strokes in a $50 \mathrm{~mL}$-glass dounce, and the homogenate was centrifuged at $800 \mathrm{~g}$ for $20 \mathrm{~min}$. The supernatant was collected and centrifuged at $9000 \mathrm{~g}$ for $20 \mathrm{~min}$. The pellet was washed once with $0.3 \mathrm{~mol} / \mathrm{L}$ sucrose, incubated in $0.03 \mathrm{~mol} / \mathrm{L}$ sucrose for $20 \mathrm{~min}$ on ice, and then centrifuged at $14,000 \mathrm{~g}$ for $20 \mathrm{~min}$. The pellet was resuspended in double distilled water, homogenized using 10 strokes in a glass dounce, and was adjusted to $1.1 \mathrm{~mol} / \mathrm{L}$ sucrose and $5 \mathrm{mmol} / \mathrm{L}$ Tris $(\mathrm{pH} 7.5)$ in a final volume of $15 \mathrm{~mL}$. The sample was overlaid with $14 \mathrm{~mL}$ of $0.8 \mathrm{~mol} / \mathrm{L}$ sucrose and $5 \mathrm{~mL}$ of $0.3 \mathrm{~mol} / \mathrm{L}$ sucrose, and centrifuged at $84,000 \mathrm{~g}$ for $2 \mathrm{~h}$ in SW40 rotor (Beckman). Crude SPM was collected from the interface of $0.8 \mathrm{~mol} / \mathrm{L}$ to $1.1 \mathrm{~mol} / \mathrm{L}$ sucrose, diluted with ice-cold water (1:3), and centrifuged at $200,000 \mathrm{~g}$ in an SW40 rotor for $40 \mathrm{~min}$. The resulting SPM was used to isolate lipid rafts following the method described by Sepúlveda et al. (2006). Thirteen fractions obtained from density gradient centrifugation were collected and kept at $-80^{\circ} \mathrm{C}$ for subsequent western blot analysis.

\section{RT-PCR}

The cerebral cortex, cerebellar cortex, hippocampus, and corpus striatum were dissected from Sprague-Dawley rats, and the total RNA from each tissue was isolated using TRIzol reagent. cDNA was synthesized using a random primer and an Omniscript reverse transcription kit (Qiagen). PMCA1, PMCA2, PMCA3, and PMCA4 cDNA were amplified using the following primers (Mamic et al., 2000; Tachibana et al., 2004): PMCA1 sense 5'-GGCGACTTTGGCATCACACT-3' and anti-sense 5'-TTTCAACTTGGTGCAAATTCCA-3'; PMCA2 sense 5'-ATCCAGACACAGATCCGCGTCGTG-3' and antisense 5'-GATTTGCTCGTGTCGGTCGTCAGG-3'; PMCA3 sense 5'-ACCAGTGTATGTGCAGTACTTTGTG-3' and anti-sense 5'-CTAG- 
GTAGGACTGAACCACTGTCAT-3'; PMCA4 sense 5'-GTCTATCCTCACAGTCCTCATCCT-3' and anti-sense 5'-CTTTACAGAGTAGGCCAACGAGAT-3'. $\beta$-Actin was amplified as the housekeeping control using the primers sense 5'-GATGACCCAGATCATGTTTGA-3' and anti-sense 5'-GGGCACAGTGTGGGTGAC-3'. The RT-PCR products were electrophoresed on $2 \%$ agarose gel and visualized after ethidium bromide staining.

\section{Western blot analysis}

The cerebral cortex, cerebellar cortex, hippocampus, and corpus striatum were obtained from adult SpragueDawley rats. Soluble proteins from the tissues and cells were extracted with ice-cold RIPA buffer (50 mmol/L Tris/HCl, pH 7.4, $150 \mathrm{mmol} / \mathrm{L} \mathrm{NaCl}, 1 \% \mathrm{NP}-40,0.25 \%$ sodium deoxycholate, $1 \mathrm{mmol} / \mathrm{L}$ EDTA, $1 \mathrm{mmol} / \mathrm{L} \mathrm{NaF}$, and proteinase inhibitor cocktails). The protein concentrations were measured using a BCA protein assay kit (Pierce). Approximately $20 \mu \mathrm{g}$ of each sample was subjected to SDS-PAGE and electroblotted onto PVDF membranes (GE). After blocking with $5 \%$ nonfat dry milk in TBST $(10 \mathrm{mmol} /$ $\mathrm{L}$ Tris/ $\mathrm{HCl}, \mathrm{pH} 7.4,150 \mathrm{mmol} / \mathrm{L} \mathrm{NaCl}, 0.1 \%$ Tween-20) at room temperature for $1 \mathrm{~h}$, the membranes were incubated with proper primary antibodies overnight at $4^{\circ} \mathrm{C}$. After washing with TBST, the membranes were incubated with HRP-conjugated secondary antibodies for $1 \mathrm{~h}$ at room temperature. The immunoblots were visualized using a SuperSignal West Pico chemiluminescent substrate system (Pierce).

\section{Immunofluorescence microscopy}

The cells were fixed in $4 \%$ paraformaldehyde for $30 \mathrm{~min}$ at room temperature and were permeabilized with $1 \%$ Triton X-100 for 10 min. After blocking with $5 \%$ goat serum, the cells were incubated overnight at $4^{\circ} \mathrm{C}$ with primary antibodies in PBS. The cells were incubated for $1 \mathrm{~h}$ with FITC- and TRITC-conjugated secondary antibodies at $37^{\circ} \mathrm{C}$ before they were observed under an Olympus FV500 laser confocal scanning microscope. In some experiments, the cells were pretreated with $10 \mathrm{mmol} / \mathrm{L}$ methyl- $\beta$-cyclodextrin (M $\beta C D$ ) for $30 \mathrm{~min}$ to disrupt the lipid rafts (Zhang et al., 2009).

\section{Förster resonance energy transfer (FRET)}

FRET was employed to determine the changes in the protein-protein interaction between PMCA4b and nNOS. HEK-293 cells were transfected or cotransfected with the pEGFP-hPMCA4b, pRFP-nNOS, pEGFP-hPMCA4b-mut, pEGFP-hPMCA4b-cap, or the pRFP- $\triangle \mathrm{nNOS}$ plasmids. They were then seeded onto $30 \mathrm{~mm}$-glass coverslips at $3 \times$ $10_{4}$ cell/well, and maintained at $37^{\circ} \mathrm{C}$ for $48 \mathrm{~h}$. Subsequently, the cells were incubated in isosmotic buffer containing $145 \mathrm{mmol} / \mathrm{L} \mathrm{N}$-methyl-dglucamine, $5 \mathrm{mmol} / \mathrm{L} \mathrm{KCl}, 1 \mathrm{mmol} / \mathrm{L} \mathrm{MgCl}, 1 \mathrm{mmol} / \mathrm{L} \mathrm{CaCl} 2,10 \mathrm{mmol} / \mathrm{L}$ d-glucose, $100 \mu \mathrm{mol} / \mathrm{L}$ l-arginine, and $10 \mathrm{mmol} / \mathrm{L}$ HEPES, $\mathrm{pH}$ 7.4. The cells were treated with $1 \mu \mathrm{mol} / \mathrm{L}$ thapsigargin and $50 \mathrm{nmol} / \mathrm{L}$ ionomycin to induce a transient increase in $\left[\mathrm{Ca}^{2+}\right]$. In some experiments, the cells were pretreated with $10 \mathrm{mmol} / \mathrm{LM} \mathrm{MCD}$ for $30 \mathrm{~min}$ to impair the lipid raft microdomains before the thapsigargin/ionomycin treatment.

The changes in FRET were recorded using an UltraVIEW VoX laser confocal scanning microscope system (Perkin Elmer) equipped with a 60x, 1.4 NA oil immersion objective lens and a cultivation chamber fitted with a temperature-control and $\mathrm{CO}_{2}$-control device (Tokai $\mathrm{Hit}, 37^{\circ} \mathrm{C}, 5 \% \mathrm{CO}_{2}$ ). The cells were imaged at $8 \mathrm{~s}$-intervals for
208 s. EGFP-tagged proteins were excited at $488 \mathrm{~nm}$ and their emissions were detected at $530 \mathrm{~nm}$. RFP-tagged proteins were excited at $561 \mathrm{~nm}$ and their emissions were detected at $615 \mathrm{~nm}$. Cells transfected with empty vector (pcDNA3.1) were used for background correction. The FRET method was carried out as described by Youvan (1997), with minor modifications. Cells expressing donor and acceptor construct were used to compensate for the signal in the FRET channel (excitation: $488 \mathrm{~nm}$, emission: $615 \mathrm{~nm}$ ) for spectral bleed through and cross-excitation ( $a$ and $b$ value).

net FRET $(\mathrm{nF})$ was calculated using the following equation:

net FRET = FRET signal $-(a \times$ RFP signal $)-(b \times$ EGFP signal $)$.

Both RFP and EGFP signals were observed in the cell, and appropriate percentages of these two signals must be subtracted from any signal measured in the FRET channel. This procedure was done on the entire image using some type of image arithmetic, or it can be done on a pixel-by-pixel basis at specific cellular substructures. The images and data analysis were processed with Volocity software (Perkin Elmer).

\section{$\left[\mathrm{Ca}^{2+}\right]_{\mathrm{i}}$ and $[\mathrm{NO}]_{\mathrm{i}}$ assays}

The $\left[\mathrm{Ca}^{2+}\right]_{i}$ of individual cells and PMCA activity were assayed using Fura-2-AM, as previously described (Zhang et al., 2009). NO production in individual cells was monitored using the NO-sensitive fluorescence probe DAF-2-DA (Kojima et al., 1998; Zhou and He, 2011). The primary cerebellar granule cells or HEK-293 cells were loaded with $2 \mu \mathrm{mol} / \mathrm{L}$ Fura-2-AM or $1 \mu \mathrm{mol} / \mathrm{L}$ DAF-2-DA in serum-free DMEM for $30 \mathrm{~min}$ at $37^{\circ} \mathrm{C}$, and then incubated in isosmotic buffer containing $145 \mathrm{mmol} / \mathrm{L} \mathrm{N}$-methyl-d-glucamine, $5 \mathrm{mmol} / \mathrm{L} \mathrm{KCl}, 1 \mathrm{mmol} / \mathrm{L}$ $\mathrm{MgCl}_{2}, 1 \mathrm{mmol} / \mathrm{L} \mathrm{CaCl}_{2}, 10 \mathrm{mmol} / \mathrm{L}$ d-glucose, $100 \mu \mathrm{mol} / \mathrm{L} \mathrm{l-arginine}$, and $10 \mathrm{mmol} / \mathrm{L}$ HEPES, $\mathrm{pH}$ 7.4. We added $100 \mu \mathrm{mol} / \mathrm{L}$ glutamate, $10 \mu \mathrm{mol} / \mathrm{L}$ of glycine plus $1 \mu \mathrm{mol} / \mathrm{L}$ of thapsigargin to the cerebellar granule cells to induce a glutamate receptor-coupled increase in $\left[\mathrm{Ca}^{2+}\right]_{\mathrm{i}}$, whereas $1 \mu \mathrm{mol} / \mathrm{L}$ thapsigargin and $50 \mathrm{nmol} / \mathrm{L}$ ionomycin were added to the HEK-293 cells to induce a transient increase in $\left[\mathrm{Ca}^{2+}\right]_{\mathrm{i}}$ (Zhang et al., 2009). The changes in fluorescence intensity of Fura-2-loaded cells at $340 \mathrm{~nm} / 380 \mathrm{~nm}$ excitation and $510 \mathrm{~nm}$ emission wavelengths and those of DAF-2-loaded cells at $490 \mathrm{~nm}$ excitation and $515 \mathrm{~nm}$ emission wavelengths were recorded under a Nikon TE2000 inverted epifluorescence microscope equipped with a $40 \times$ oil immersion objective lens and a Sutter filter wheel. In all experiments, the objective was focused on cell somata rather than neurites. The time courses for $\left[\mathrm{Ca}^{2+}\right]_{i}$ and $[\mathrm{NO}]_{i}$ were plotted from a minimum of 20 randomly selected cell somata.

\section{ACKNOWLEDGEMENTS}

This work was supported by grants from the National Basic Research Program of China (Grant Nos. 2010CB833701 and 2012CB934003) and the National Natural Science Foundation of China (Grant No. 31070736). We would like to thank Profs. Pingsheng Liu, Youguo Huang, and Xujia Zhang (Institute of Biophysics, CAS) for their valuable suggestions and discussions. We are also indebted to Wenmin Zhong (Institute of Biophysics, CAS) for her technical assistance.

\section{REFERENCES}

Adamo, H.P., Filoteo, A.G., Enyedi, A., and Penniston, J.T. (1995). Mu- 
tants in the putative nucleotide-binding region of the plasma membrane $\mathrm{Ca}(2+)$-pump. A reduction in activity due to slow dephosphorylation. J Biol Chem 270, 30111-30114.

Alderton, W.K., Cooper, C.E., and Knowles, R.G. (2001). Nitric oxide synthases: structure, function and inhibition. Biochem J 357, 593-615.

Brenman, J.E., Chao, D.S., Gee, S.H., McGee, A.W., Craven, S.E., Santillano, D.R., Wu, Z., Huang, F., Xia, H., Peters, M.F., et al. (1996). Interaction of nitric oxide synthase with the postsynaptic density protein PSD-95 and alpha1-syntrophin mediated by PDZ domains. Cell 84, 757-767.

Brini, M. (2009). Plasma membrane $\mathrm{Ca}(2+)-A T P a s e:$ from a housekeeping function to a versatile signaling role. Pflugers Arch 457, 657-664.

Brini, M., and Carafoli, E. (2009). Calcium pumps in health and disease. Physiol Rev 89, 1341-1378.

Brown, D.A., and London, E. (1998). Functions of lipid rafts in biological membranes. Annu Rev Cell Dev Biol 14, 111-136.

Calabrese, V., Mancuso, C., Calvani, M., Rizzarelli, E., Butterfield, D.A., and Stella, A.M. (2007). Nitric oxide in the central nervous system: neuroprotection versus neurotoxicity. Nat Rev Neurosci 8, 766-775.

Carafoli, E. (2003). The calcium-signalling saga: tap water and protein crystals. Nat Rev Mol Cell Biol 4, 326-332.

Cartwright, E.J., Oceandy, D., and Neyses, L. (2009). Physiological implications of the interaction between the plasma membrane calcium pump and nNOS. Pflugers Arch 457, 665-671.

Ciruela, F. (2008). Fluorescence-based methods in the study of protein-protein interactions in living cells. Curr Opin Biotechnol 19, 338-343.

Corradi, G.R., and Adamo, H.P. (2007). Intramolecular fluorescence resonance energy transfer between fused autofluorescent proteins reveals rearrangements of the $\mathrm{N}$ - and $\mathrm{C}$-terminal segments of the plasma membrane $\mathrm{Ca} 2+$ pump involved in the activation. $\mathrm{J}$ Biol Chem 282, 35440-35448.

Dudek, H., Datta, S.R., Franke, T.F., Birnbaum, M.J., Yao, R., Cooper, G.M., Segal, R.A., Kaplan, D.R., and Greenberg, M.E. (1997). Regulation of neuronal survival by the serine-threonine protein kinase Akt. Science 275, 661-665.

Falchetto, R., Vorherr, T., Brunner, J., and Carafoli, E. (1991). The plasma membrane $\mathrm{Ca} 2+$ pump contains a site that interacts with its calmodulin-binding domain. J Biol Chem 266, 2930-2936.

Falchetto, R., Vorherr, T., and Carafoli, E. (1992). The calmodulinbinding site of the plasma membrane $\mathrm{Ca} 2+$ pump interacts with the transduction domain of the enzyme. Protein Sci 1, 1613-1621.

Fujimoto, T. (1993). Calcium pump of the plasma membrane is localized in caveolae. J Cell Biol 120, 1147-1157.

Guerini, D. (1998). The significance of the isoforms of plasma membrane calcium ATPase. Cell Tissue Res 292, 191-197.

Guix, F.X., Uribesalgo, I., Coma, M., and Munoz, F.J. (2005). The physiology and pathophysiology of nitric oxide in the brain. Prog Neurobiol 76, 126-152.

Hammes, A., Oberdorf-Maass, S., Rother, T., Nething, K., Gollnick, F., Linz, K.W., Meyer, R., Hu, K., Han, H., Gaudron, P., et al. (1998). Overexpression of the sarcolemmal calcium pump in the myocardium of transgenic rats. Circ Res 83, 877-888.

Holton, M., Mohamed, T.M., Oceandy, D., Wang, W., Lamas, S., Emerson, M., Neyses, L., and Armesilla, A.L. (2010). Endothelial nitric oxide synthase activity is inhibited by the plasma membrane calcium ATPase in human endothelial cells. Cardiovasc Res 87, 440-448.

Jiang, L., Fernandes, D., Mehta, N., Bean, J.L., Michaelis, M.L., and Zaidi, A. (2007). Partitioning of the plasma membrane Ca2+-ATPase into lipid rafts in primary neurons: effects of cholesterol depletion. J Neurochem 102, 378-388.

Kim, E., DeMarco, S.J., Marfatia, S.M., Chishti, A.H., Sheng, M., and Strehler, E.E. (1998). Plasma membrane Ca2+ ATPase isoform 4b binds to membrane-associated guanylate kinase (MAGUK) proteins via their PDZ (PSD-95/Dlg/ZO-1) domains. J Biol Chem 273, 1591-1595.

Kim, W.K., Choi, Y.B., Rayudu, P.V., Das, P., Asaad, W., Arnelle, D.R., Stamler, J.S., and Lipton, S.A. (1999). Attenuation of NMDA receptor activity and neurotoxicity by nitroxyl anion, NO. Neuron 24 , 461-469.

Kobe, B., and Kemp, B.E. (1999). Active site-directed protein regulation. Nature 402, 373-376.

Kojima, H., Nakatsubo, N., Kikuchi, K., Urano, Y., Higuchi, T., Tanaka, J., Kudo, Y., and Nagano, T. (1998). Direct evidence of NO production in rat hippocampus and cortex using a new fluorescent indicator: DAF-2 DA. Neuroreport 9, 3345-3348.

Kruger, W.A., Yun, C.C., Monteith, G.R., and Poronnik, P. (2009). Muscarinic-induced recruitment of plasma membrane Ca2+-ATPase involves PSD-95/Dlg/Zo-1-mediated interactions. J Biol Chem 284, 1820-1830.

Loura, L.M., and Prieto, M. FRET in Membrane Biophysics: An Overview. (2011). Front Physiol 2, 82.

Mamic, T.M., Holman, N.A., Roberts-Thomson, S.J., and Monteith, G.R. (2000). PMCA1 mRNA expression in rat aortic myocytes: a real-time RT-PCR study. Biochem Biophys Res Commun 276, 1024-1027.

Miyawaki, A. Development of probes for cellular functions using fluorescent proteins and fluorescence resonance energy transfer. (2011) Annu Rev Biochem 80, 357-373.

Mohamed, T.M., Oceandy, D., Prehar, S., Alatwi, N., Hegab, Z., Baudoin, F.M., Pickard, A., Zaki, A.O., Nadif, R., Cartwright, E.J., et al. (2009). Specific role of neuronal nitric-oxide synthase when tethered to the plasma membrane calcium pump in regulating the beta-adrenergic signal in the myocardium. J Biol Chem 284, 12091-12098.

Mohamed, T.M., Oceandy, D., Zi, M., Prehar, S., Alatwi, N., Wang, Y., Shaheen, M.A., Abou-Leisa, R., Schelcher, C., Hegab, Z., et al. (2011). Plasma membrane calcium pump (PMCA4)-neuronal nitricoxide synthase complex regulates cardiac contractility through modulation of a compartmentalized cyclic nucleotide microdomain. J Biol Chem 286, 41520-41529.

Moncada, S., and Bolanos, J.P. (2006). Nitric oxide, cell bioenergetics and neurodegeneration. J Neurochem 97, 1676-1689.

Moro, M.A., Cardenas, A., Hurtado, O., Leza, J.C., and Lizasoain, I. (2004). Role of nitric oxide after brain ischaemia. Cell Calcium 36, 265-275.

Oceandy, D., Mohamed, T.M., Cartwright, E.J., and Neyses, L. (2010). Local signals with global impacts and clinical implications: lessons from the plasma membrane calcium pump (PMCA4). Biochim Biophys Acta 1813, 974-978.

Oceandy, D., Stanley, P.J., Cartwright, E.J., and Neyses, L. (2007). The 
regulatory function of plasma-membrane $\mathrm{Ca}(2+)$-ATPase (PMCA) in the heart. Biochem Soc Trans 35, 927-930.

Pacher, P., Beckman, J.S., and Liaudet, L. (2007). Nitric oxide and peroxynitrite in health and disease. Physiol Rev 87, 315-424.

Parton, R.G. (2001). Cell biology. Life without caveolae. Science 293, 2404-2405.

Piehler, J. (2005). New methodologies for measuring protein interactions in vivo and in vitro. Curr Opin Struct Biol 15, 4-14.

Sagami, I., Daff, S., and Shimizu, T. (2001). Intra-subunit and inter-subunit electron transfer in neuronal nitric-oxide synthase: effect of calmodulin on heterodimer catalysis. J Biol Chem 276, 30036-30042.

Schuh, K., Uldrijan, S., Gambaryan, S., Roethlein, N., and Neyses, L. (2003). Interaction of the plasma membrane Ca2+ pump $4 \mathrm{~b} / \mathrm{Cl}$ with the $\mathrm{Ca} 2+/$ calmodulin-dependent membrane-associated kinase CASK. J Biol Chem 278, 9778-9783.

Schuh, K., Uldrijan, S., Telkamp, M., Rothlein, N., and Neyses, L. (2001). The plasmamembrane calmodulin-dependent calcium pump: a major regulator of nitric oxide synthase I. J Cell Biol 155, 201-205.

Sepulveda, M.R., Berrocal-Carrillo, M., Gasset, M., and Mata, A.M. (2006). The plasma membrane Ca2+-ATPase isoform 4 is localized in lipid rafts of cerebellum synaptic plasma membranes. J Biol Chem 281, 447-453.

Sgambato-Faure, V., Xiong, Y., Berke, J.D., Hyman, S.E., and Strehler, E.E. (2006). The Homer-1 protein Ania-3 interacts with the plasma membrane calcium pump. Biochem Biophys Res Commun 343, 630-637.

Simons, K., and Ikonen, E. (1997). Functional rafts in cell membranes. Nature 387, 569-572.

Stamler, J.S., and Meissner, G. (2001). Physiology of nitric oxide in skeletal muscle. Physiol Rev 81, 209-237.
Strehler, E.E., and Zacharias, D.A. (2001). Role of alternative splicing in generating isoform diversity among plasma membrane calcium pumps. Physiol Rev 81, 21-50.

Tachibana, T., Ogura, H., Tokunaga, A., Dai, Y., Yamanaka, H., Seino, D., and Noguchi, K. (2004). Plasma membrane calcium ATPase expression in the rat spinal cord. Brain Res Mol Brain Res 131, 26-32.

Torreilles, F., Salman-Tabcheh, S., Guerin, M., and Torreilles, J. (1999). Neurodegenerative disorders: the role of peroxynitrite. Brain Res Brain Res Rev 30, 153-163.

Tran, M.H., Yamada, K., Nakajima, A., Mizuno, M., He, J., Kamei, H., and Nabeshima, T. (2003). Tyrosine nitration of a synaptic protein synaptophysin contributes to amyloid beta-peptide-induced cholinergic dysfunction. Mol Psychiatry 8, 407-412.

Williams, J.C., Armesilla, A.L., Mohamed, T.M., Hagarty, C.L., McIntyre, F.H., Schomburg, S., Zaki, A.O., Oceandy, D., Cartwright, E.J., Buch, M.H., et al. (2006). The sarcolemmal calcium pump, alpha-1 syntrophin, and neuronal nitric-oxide synthase are parts of a macromolecular protein complex. J Biol Chem 281, 23341-23348.

Youvan, D.C., Silva, C.M., Bylina, E.J., Coleman, W.J., Dilworth, M.R., and Yang, M.M. (1997). Calibration of fluorescence resonance energy transfer in microscopy using genetically engineered GFP derivatives on Nickel chelating beads. Biotechnology et alia 3, 1-18.

Zhang, J., Xiao, P., and Zhang, X. (2009). Phosphatidylserine externalization in caveolae inhibits $\mathrm{Ca} 2+$ efflux through plasma membrane Ca2+-ATPase in ECV304. Cell Calcium 45, 177-184.

Zhou, L., and Zhu, D.Y. (2009). Neuronal nitric oxide synthase: structure, subcellular localization, regulation, and clinical implications. Nitric Oxide 20, 223-230.

Zhou, X., and He, P. (2011). Improved measurements of intracellular nitric oxide in intact microvessels using 4,5-diaminofluorescein diacetate. Am J Physiol Heart Circ Physiol 301, H108-114. 